\title{
Identification of the internal combustion engine malfunctions based on the vibrations of the vehicle body
}

Selected parameters of an IC engine were correlated with vibrations transferred to the vehicle body with the aim of identifying engine malfunctions. Registered acceleration component signals were analyzed in the aspect of frequency. A reasoning model based on devised identification matrix was used to classify obtained data. This allowed the authors to estimate the possibility of research object damage/malfunctions with an assumed degree of probability.

Key words: vibrations, vehicle diagnostics, Fourier transform

\section{Introduction}

An internal combustion engine is a machine that transforms chemical energy delivered in the fuel into mechanical work. Due to the fact that in most engines the combustion occurs inside them (within engine cylinders), mechanical work is generated in a repetitive manner. The combustion itself is a very intense process that generates large impulses of thermal energy that is being transferred to the crank and piston system, causing engine vibrations, which are further transferred to the vehicle chassis through the engine mounting points. These vibrations generate a characteristic vibration spectrum during engine operation. The course of this spectrum is dependent on several factors, such as engine type (number of engine strokes), number of cylinders and current crankshaft rotational speed. Characteristic spectral lines can be observed on the vibration spectrum, which are total multiples of crankshaft speed and number of engine cylinders, while also being dependent on engine type. In a single-cylinder four-stroke engine, the combustion process occurs at every other complete turn of the crankshaft, therefore the basic spectral line is equal to $1 / 2$ of crankshaft speed. In nomenclature related to spectral analysis, these are often called the vibrations of the $n$-th order- in this case of $1 / 2$ th order. If a multi-cylinder engine is in good operating condition (meaning the combustion occurs in all cylinders in a similar manner), the vibrations of the $\mathrm{n}$-th order may be very small (from 0.003 to $0.009 \mathrm{~m} / \mathrm{s}$ ), making spectral analysis difficult. In a situation when of the cylinders generates less work than the others (engine malfunction), spectral lines of the $\mathrm{n}$-th order are more pronounced. The signal can then rise above the level of $0.009 \mathrm{~m} / \mathrm{s}$ to above $0.03 \mathrm{~m} / \mathrm{s}$ during breaks that occur in the combustion of fuelair mixture. Several engine malfunctions can contribute to breaks in combustion, including damaged spark plug wires, faulty injector, broken piston ring, low compression ratio or leaking valves. Each of those malfunctions can result in different courses of spectral lines.

IC engines work in a repetitive manner, which means that the dynamic gas forces acting on each of the pistons cause periodic accelerations of the engine crankshaft, which is additionally subjected to torsional, bending and longitudal vibrations [10]. Therefore, a dynamic gas force acting on each crank of the crankshaft changes periodically with time, and therefore can be divided into Fourier series. Then, separate elements of the series cause changes in amplitude values for harmonic components of the spectrum [7, 8]. The analysis of vibration velocity peak value of the investigated spectrum is a diagnostic method that is commonly used to assess the machine's technical condition [1-4]. Therefore, spectral components have to be analyzed to locate the malfunction, identify and assess its causes [9]. According to [5, 6], a frequency band of up to $\mathrm{n}$ basic ordinates can point to the occurrence of malfunctions in IC engine operation. Basing on that conclusion, an indirect method for diagnosing IC engine malfunctions using the analysis of harmonic components of a vehicle chassis amplitude spectrum.

\section{Research object}

A Polaris ATV (All-Terrain Vehicle) was used as a research object in this study. It was equipped with an authordevised integrated measurement system comprised of a wireless data transmission system compatible with CAN BUS and an acceleration sensor. The wireless transmitter is plugged into the DTC socket located in the vehicle's engine compartment. After plugging the interface in and turning on the vehicle's ignition, the interface is synchronized with the vehicle on-board data transmission network. The microprocessor built within the interface is connected to a transceiver which converts the signal from the vehicle and sends the data to a computer with the use of a radio transmitter working in the frequency of $433 \mathrm{MHz}$ utilizing UART serial transmission in the range of up to 1 kilometer. The interface is shown in Fig. 1.

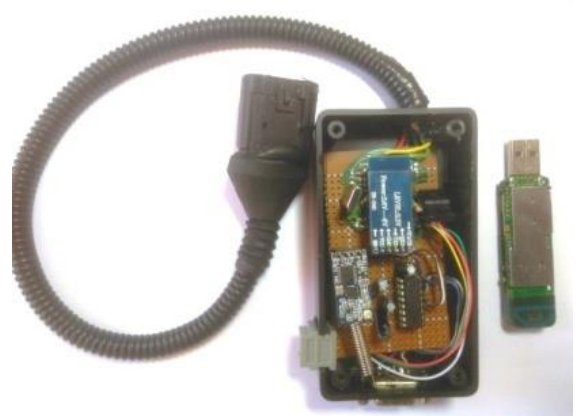

Fig. 1. Interface with a USB receiver 
The research object was also equipped with a sensor for direct acceleration measurement (3DM-GX3-25). This sensor is made with the use of MEMS technology and is therefore resistant to electrical noise of the conditioning units thanks to using a series of sensors with a PWM impulse output. It has a built-in processor which ensures static and dynamic orientation of measurement axes thanks to utilizing a measurement synthesis algorithm.

Basic parameters of the sensor are given below:

Attitude heading range: $360^{\circ}$ about all 3 axes

Accelerometer range: $\quad \pm 5 \mathrm{~g}$ standard

Gyroscope range:

Static accuracy:

$\pm 300^{\circ} / \mathrm{sec}$ standard

$\pm 0.5^{\circ}$ pitch, roll, heading typical

for static test conditions

Data output rate:

Filtering:

\section{up to $1000 \mathrm{~Hz}$}

sensors sampled at $30 \mathrm{kHz}$, digitally filtered (user adjustable) and scaled into physical units; coning and sculling integrals computed at $1 \mathrm{kHz}$

Interface:

$$
\text { RS232 }
$$

Baud rate:

$$
115,200 \text { bps to } 921,600 \mathrm{bps}
$$

Power supply voltage: $\quad+3.2$ to +16 volts DC

This sensor was used to register vibrations caused by an operating IC engine mounted in the central part of the vehicle chassis (Fig. 2).

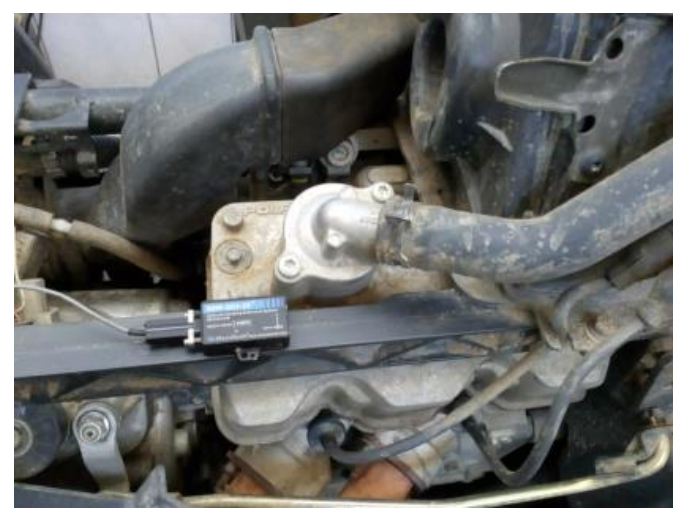

Fig. 2. Placement of the 3DM-GX3-25 sensor on the vehicle during tests

The orientation of the sensor in relation to engine crankshaft is as follows: $\mathrm{x}$ axis - transverse, y axis - longitudal, $\mathrm{z}$ axis - vertical.

A part of the designed system is a proprietary software solution (Fig. 3) allowing the user to preview current vehicle operating parameters and save the data to the computer's hard disk.

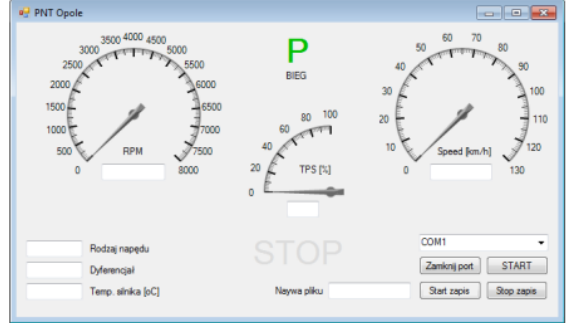

Fig. 3. Author-developed software in operation

\section{Signal analysis}

Signal registered with the acceleration sensor was analyzed using the Short-Time Fourier Transform (STFT). When using the STFT method, the input signal is first divided into smaller segments, for which the signal can be treated as quasi-stationary. Then, separate segments are processed with the use of FFT algorithm. STFT is described by equation (1), whereas the entry signal window is described by equation (2).

$$
\begin{gathered}
\operatorname{STFT}\left[\mathrm{x}_{\mathrm{w}}(\mathrm{t}, \tau)\right]=\int_{-\infty}^{\infty} \mathrm{w}(\mathrm{t}, \tau) \mathrm{x}(\mathrm{t}) \mathrm{e}^{-\mathrm{j} 2 \pi \mathrm{ft}} \mathrm{dt} \\
\mathrm{xw}(\mathrm{t}, \tau)=\mathrm{w}(\mathrm{t}, \tau) \mathrm{x}(\mathrm{t})
\end{gathered}
$$

A comparison of obtained spectra represents a frequential-spectral map of the analyzed signal. A weighted function $\mathrm{w}(\mathrm{t}, \tau)$ extracts the data segments from the input signalfor subsequent FFT analysis.

The results of a Short-Time Fourier Transform (STFT) are obtained as a discrete matrix $\mathrm{H}$, containing a $\mathrm{k}$ number of short-time spectra, with a particular number of spectral lines. The number of short-time spectra k (Equation 3) is equal to the number of STFT iterations and is dependent of total input signal sample quantity $M$ subjected to STFT analysis, data segment size $\mathrm{N}$ correspondent to time sequence length used for STFT analysis and a time displacement increment for the segment (s).

$$
\mathrm{k}=\operatorname{Ent}\left(\frac{\mathrm{M}-\mathrm{N}}{\mathrm{s}}\right)+1
$$

A data segment $\mathrm{N}$ should contain a minimum of two signal intervals (important signal component of the lowest frequency). Taking these considerations into account, an optimum number of samples in a data segment for STFT analysis can be calculated using Equation (4).

$$
\mathrm{N} \geq \frac{2 \cdot \mathrm{f}_{\mathrm{s}}}{\mathrm{f}_{\mathrm{l}}}
$$

Changes in amplitude spectrum obtained with the use of STFT method are shown in Figs 4-6. Obtained courses show the occurrence of clearly visible amplitudes in the basic frequency range $f_{1}$, as well for the other harmonics of

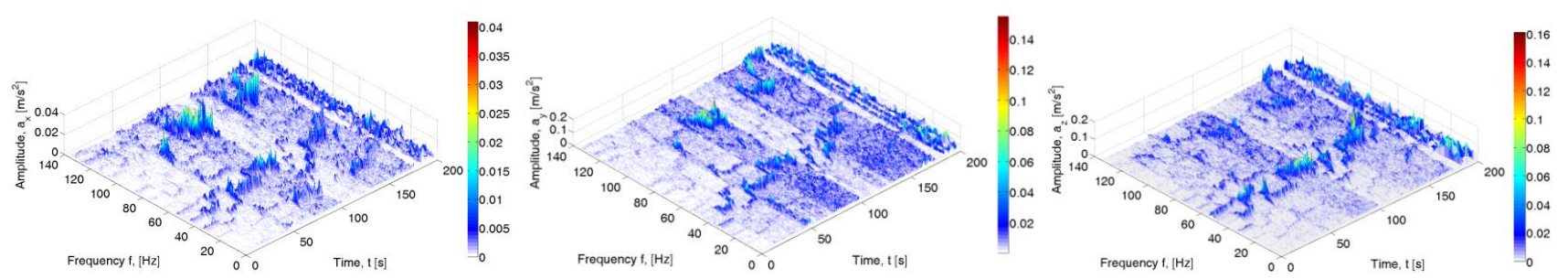

Fig. 4. STFT spectrum for an operational IC engine 

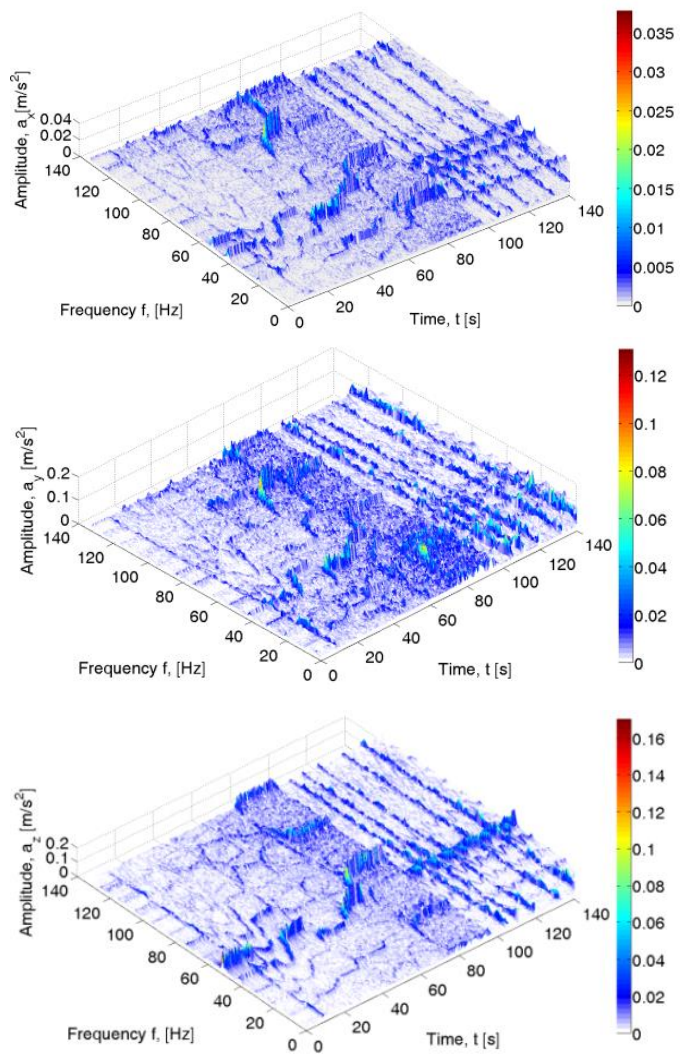

Fig. 5. STFT spectrum for a malfunctioning IC engine - time gap in fuel injection
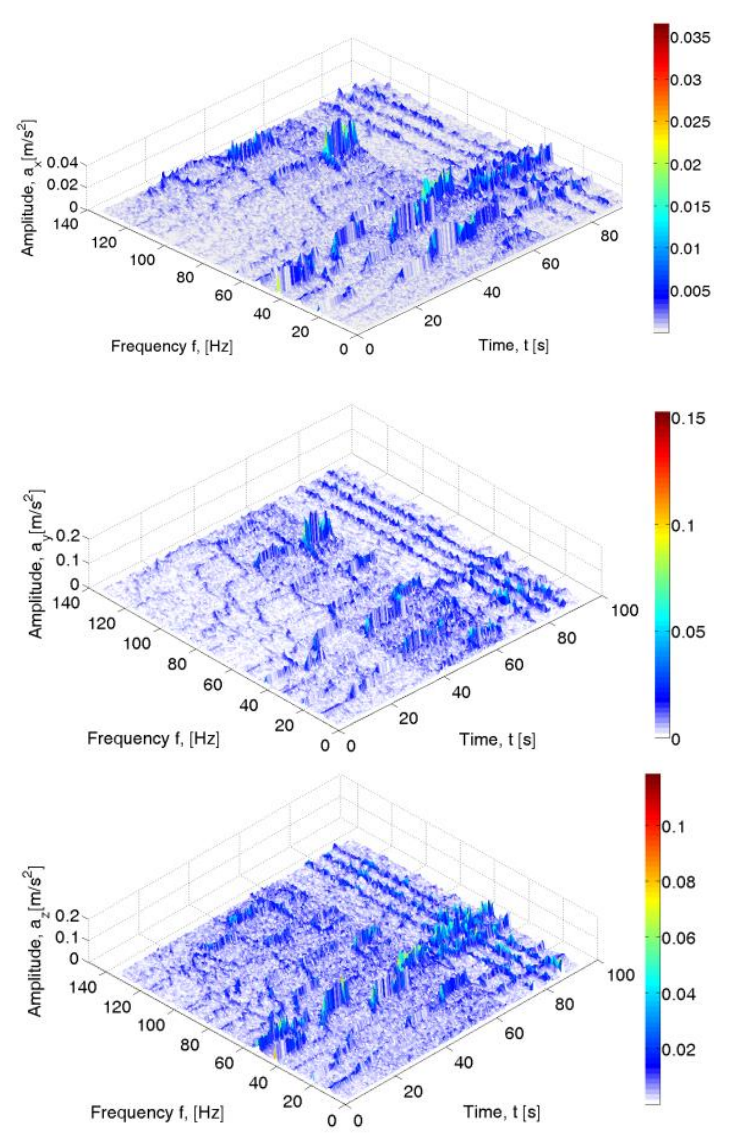

Fig. 6.STFT spectrum for a malfunctioning IC engine - identified air leak in one of the cylinders the $n$-th order $\left(f_{0.5}, f_{1.5} f_{2}, f_{2.5}\right)$ for different states of the research object. Next, identified engine malfunctions were subjected to the analysis of changes in amplitude spectrum.

An engine rotational speed profile with a time window set to 3 seconds was used to analyze the acceleration signal in the aspect of its frequency, as shown in Fig. 7.

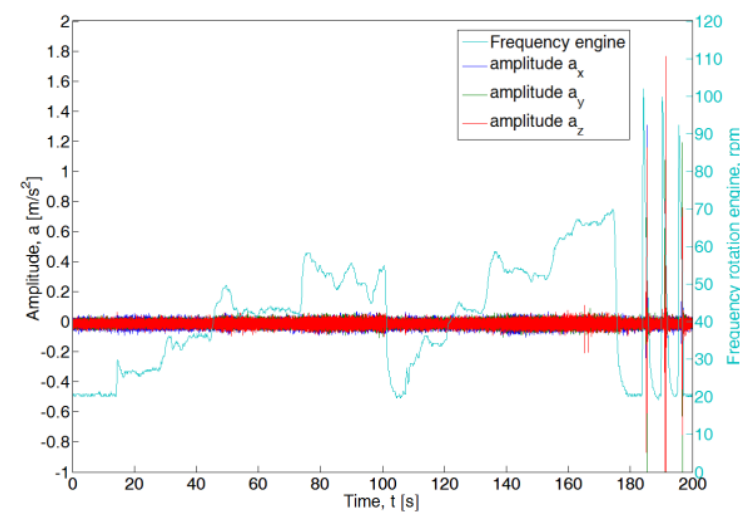

Fig. 7. Engine speed profile for an operational engine

The following acceleration component values were noted for a roadworthy engine operating on idle: $\mathrm{a}_{\mathrm{x}}=0.004$ $\mathrm{m} / \mathrm{s}^{2}$ for $\mathrm{f}_{1}$ harmonic, $\mathrm{a}_{\mathrm{y}}=0.03 \mathrm{~m} / \mathrm{s}^{2}$ for $\mathrm{f}_{1.5}$ harmonican $\mathrm{da}_{\mathrm{z}}=$ $0.04 \mathrm{~m} / \mathrm{s}^{2}$ for $\mathrm{f}_{2.5}$ harmonic (Fig. 8). Introducing engine malfunctions in the form of removing and injector or a spark plug in one of the cylinders have resulted in a significant increase of $a_{x}$ and $a_{z}$ amplitude values (Fig. 8).

An increase in amplitude values is also visible for other ranges of engine speeds. An example graph showcasing the course for 2500 rpm is shown in Fig. 9.

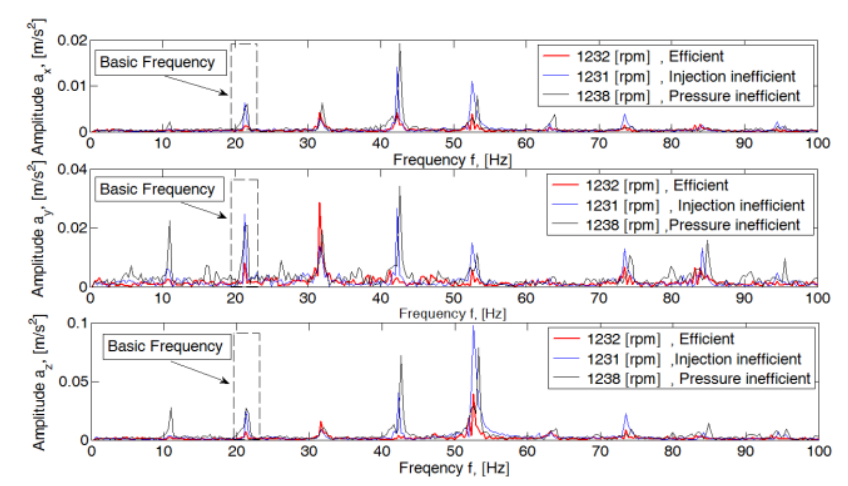

Fig. 8. FFT spectral amplitude for $1200 \mathrm{rpm}$

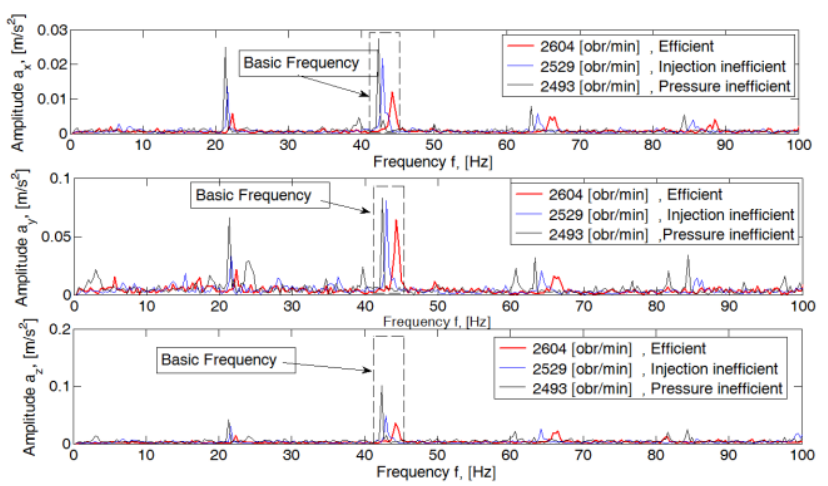

Fig. 9. FFT spectral amplitude for $2500 \mathrm{rpm}$ 
Basing on the known crankshaft speed, its base frequency $\mathrm{f}_{1}$ was determined with the use of $\pm 1.5 \mathrm{~Hz}$ frequency intervals. Next, dominant values of acceleration components of the $n$-th order $\left(n=f_{0.5} f_{1}, f_{1.5} f_{2}, f_{2.5}\right)$. These values were labelled as $a_{x 0.5}, a_{x 1}, a_{x 1.5} a_{x n}$ and entered into the input data table (Table 1). Determined acceleration components correspond to a particular measurement axis (i.e. $a_{x}$ ) and engine speed (i.e. $1200 \mathrm{rpm}$ ). Input data tables were formulated for corresponding measurement axes and engine speeds. Next, relative values for different harmonics in relation to base frequency were devised. Obtained values were labelled $A_{x}$ for corresponding harmonic components of the signal spectrum.

Table 1. Input data table

\begin{tabular}{|c|c|c|c|}
\hline $\mathrm{f}$ & $\mathrm{a}_{\mathrm{x}}$ & Relative value & $\mathrm{A}_{\mathrm{x}}$ \\
\hline $\mathrm{f}_{0.5}$ & $\mathrm{a}_{\mathrm{x} 0.5} \longrightarrow \mathrm{A}_{\mathrm{x} 0.5}$ \\
\hline $\mathrm{f}_{1}$ & $\mathrm{a}_{\mathrm{x} 1}$ & $\frac{\mathrm{a}_{\mathrm{x} 0.5} * 100}{\mathrm{a}_{\mathrm{x} 1}}$ & $\mathrm{~A}_{\mathrm{x} 1}$ \\
\hline $\mathrm{f}_{1.5}$ & $\mathrm{a}_{\mathrm{x} 1.5}$ & $\frac{\mathrm{a}_{\mathrm{xn}} * 100}{\mathrm{a}_{\mathrm{x} 1}}$ & $\mathrm{~A}_{\mathrm{xn}}$ \\
\hline $\mathrm{f}_{2}$ & $\mathrm{a}_{\mathrm{x} 2}$ & $\ldots \ldots$ & $\ldots \ldots$ \\
\hline $\mathrm{f}_{2.5}$ & $\mathrm{a}_{\mathrm{x} 2.5}$ & $\ldots \ldots$ & $\ldots \ldots$ \\
\hline
\end{tabular}

Terms specifying relations for harmonics of the spectrum were assumed for residuals. Obtained values are relative to signal values of the base frequency (Table 2).

Table 2. Residualspecifyingtable for $1200 \mathrm{rpm}$

\begin{tabular}{|c|c|c|c|c|}
\hline \multirow[t]{2}{*}{$\begin{array}{l}\text { No } \\
\text { resid. }\end{array}$} & \multirow[t]{2}{*}{ Limit state WS } & \multicolumn{3}{|c|}{$\begin{array}{l}\text { Logical value MD of benchmark data for } \\
\text { specified engine condition }\end{array}$} \\
\hline & & Operational & No injector & $\begin{array}{l}\text { No spark } \\
\text { plug }\end{array}$ \\
\hline 1 & $\mathrm{~A}_{\mathrm{x} 1.0}>\mathrm{A}_{\mathrm{x} 0,5}$ & MD11 = 1 & MD21 = 1 & MD31 = 1 \\
\hline 2 & $\mathrm{~A}_{\mathrm{x} 1.5}>\mathrm{A}_{\mathrm{x} 1}$ & $\mathrm{MD} 12=1$ & MD22 = 1 & MD32 $=0$ \\
\hline 3 & $\left(\mathrm{~A}_{x 1.5}+\mathrm{A}_{\mathrm{x} 0.5}\right)>\mathrm{A}_{\mathrm{x} 1}$ & MD13 = 1 & $\mathrm{MD} 23=0$ & $\mathrm{MD} 33=0$ \\
\hline 4 & $\mathrm{~A}_{\mathrm{x} 2}>\mathrm{A}_{\mathrm{x} 1.5}$ & $\mathrm{MD} 14=1$ & MD24 = 1 & MD34 = 1 \\
\hline 5 & $\mathrm{~A}_{\mathrm{x} 2.5}>\mathrm{A}_{\mathrm{x} 2}$ & MD15 = 1 & $\mathrm{MD} 25=0$ & MD35 = 1 \\
\hline 6 & $\left(\mathrm{~A}_{x 2.5}+\mathrm{A}_{\mathrm{x} 1.5}\right)>\mathrm{A}_{\mathrm{x} 2}$ & MD16 = 1 & MD26 = 1 & MD36 $=0$ \\
\hline
\end{tabular}

Table 3. Benchmark values of residuals for $1200 \mathrm{rpm}$

\begin{tabular}{|c|c|}
\hline Limit stateWS & Logical value ME for experimental data \\
\hline $\mathrm{A}_{\mathrm{x} 10}>\mathrm{A}_{\mathrm{x} 0.5}$ & ME1 \\
\hline $\mathrm{A}_{\mathrm{x} 1.5}>\mathrm{A}_{\mathrm{x} 1}$ & ME2 \\
\hline$\left(\mathrm{A}_{\mathrm{x} 1.5}+\mathrm{A}_{\mathrm{x} 0.5}\right)>\mathrm{A}_{\mathrm{x} 1}$ & ME3 \\
\hline $\mathrm{A}_{\mathrm{x} 2}>\mathrm{A}_{\mathrm{x} 1.5}$ & ME4 \\
\hline $\mathrm{A}_{\mathrm{x} 2.5}>\mathrm{A}_{\mathrm{x} 2}$ & ME5 \\
\hline$\left(\mathrm{A}_{\mathrm{x} 2.5}+\mathrm{A}_{\mathrm{x} 1.5}\right)>\mathrm{A}_{\mathrm{x} 2}$ & ME6 \\
\hline
\end{tabular}

The data of the reference matrix (MD1n, MD2n, MD3n) of individual residues (from 1 to 6 ) are then compared with the residues of the analyzed signal Men (Table 3). If the compared data is compatible (eg MD12 and ME2), the value of WI in table 4 is 0 .

This solution does not precisely point towards the existing identification state of the object. Instead, it shows the probability of its symptoms occurring in relation to the research object. The biggest value of MD-n sum of determinants identifies the occurrence of a particular malfunction with specified probability.
For the identified engine state, a set of chosen possible malfunctions WI was determined. These malfunctions are understood as destructive occurrences leading to detetoriation in engine operation.

Table 4. IC engine identification table for $1200 \mathrm{rpm}$

\begin{tabular}{|c|c|c|c|}
\hline $\begin{array}{l}\text { Comparison of } \\
\text { readings (logi- }\end{array}$ & \multicolumn{3}{|c|}{$\begin{array}{l}\text { Logical value of state identification determinant } \\
\qquad \text { WI }\end{array}$} \\
\hline MD11 $\Leftrightarrow$ ME1 & $\begin{array}{c}0=\text { compatible } \\
1=\text { incompa- } \\
\text { tible }\end{array}$ & $\begin{array}{c}0=\text { compatible } \\
1=\text { incompa- } \\
\text { tible }\end{array}$ & $\begin{array}{c}0=\text { compatible } \\
1=\text { incompa- } \\
\text { tible }\end{array}$ \\
\hline MD12 $\Rightarrow$ ME2 & $\rightarrow \ldots .$. & & \\
\hline MHO13 $\Rightarrow$ ME3 & $\ldots \ldots$ & & \\
\hline MD14 $\Leftrightarrow$ ME4 & $\ldots \ldots$ & & \\
\hline MD15 $\Leftrightarrow$ ME5 & $\ldots \ldots$ & & \\
\hline MD16 $\Leftrightarrow$ ME6 & $\cdots \cdots$ & & \\
\hline & $\begin{array}{l}\text { Percentage } \\
\text { share } \\
\text { WS1n }=0\end{array}$ & $\begin{array}{l}\text { Percentage } \\
\text { share } \\
\text { WS3n }=0\end{array}$ & $\begin{array}{l}\text { Percentage } \\
\text { share } \\
\text { WS } 3 n=0\end{array}$ \\
\hline
\end{tabular}

A diagnostic matrix-based reasoning algorithm was created to identify engine malfunctions. The diagnostic signal should allow the user to detect faults which cause the appearance of state identification determinant, which assumes logical values of 1 or 0 (sympton). RFS relation for the investigated signal can be defined with the use of Binary Method.

\section{Identification matrix}

Obtained experimental data was analyzed with the use of described method basing on diagnostic matrix to identify malfunctions of the research object. A working example was shown for experimental data obtained for an engine speed of $1200 \mathrm{rpm}$. Values of acceleration components for $\mathrm{x}, \mathrm{y}, \mathrm{z}$ axes, specific frequency ranges (in relation to base frequency) and assumed state of the engine were shown in Fig. 8. Relative values were then determined for this portion of experimental data.

Table 5. Data analysis for $1200 \mathrm{rpm}$ in $\mathrm{x}$ axis

\begin{tabular}{|c|c|c|c|c|c|c|c|c|}
\hline $\begin{array}{l}\text { No } \\
\text { re- } \\
\text { sid. }\end{array}$ & $\begin{array}{c}\text { MDx } \\
1\end{array}$ & $\begin{array}{c}\text { MDx } \\
2\end{array}$ & $\begin{array}{c}\text { MDx } \\
3\end{array}$ & $\begin{array}{c}\mathrm{ME} \\
\mathrm{x}\end{array}$ & & WIx1 & WIx2 & WIx3 \\
\hline 1 & 1 & 1 & 1 & 1 & & 0 & 0 & 0 \\
\hline 2 & 1 & 0 & 1 & 0 & & 1 & 0 & 1 \\
\hline 3 & 1 & 0 & 1 & 0 & & 1 & 0 & 1 \\
\hline 4 & 1 & 1 & 1 & 1 & & 0 & 0 & 0 \\
\hline 5 & 0 & 0 & 0 & 0 & & 0 & 0 & 0 \\
\hline 6 & 1 & 0 & 0 & 0 & & 1 & 0 & 0 \\
\hline & & & & & $\begin{array}{l}\text { WSx } \\
{[\%]}\end{array}$ & 50 & 100 & 67 \\
\hline
\end{tabular}

Benchmark data for diagnostic matrices MDx, Mdy, MDz (Tables 5-10) was obtained basing on the analysis of acceleration components and engine condition.

The determinants of the relationship (residue) of particular harmonic axes $\mathrm{x}, \mathrm{y}, \mathrm{z}$ for the efficient engine were marked in columns: MDx1, Mdy1, MDz1. For engine with damaged injection MDx2, MDy2, MDz2. For a motor with 
a non-sealed combustion chamber: MDx3, MDx3, MDx3. The markers of the analyzed signal were denoted as: MEx, MEy, MEz.

Table 6. Data analysis for $1200 \mathrm{rpm}$ in y axis

\begin{tabular}{|c|c|c|c|}
\hline $\begin{array}{c}\text { No } \\
\text { re- } \\
\text { sid. }\end{array}$ & MDy1 & $\begin{array}{c}\text { MDy } \\
2\end{array}$ & $\begin{array}{c}\text { MDy } \\
3\end{array}$ \\
\hline 1 & 1 & 1 & 0 \\
2 & 1 & 0 & 0 \\
3 & 1 & 0 & 1 \\
4 & 0 & 1 & 1 \\
5 & 1 & 0 & 0 \\
6 & 1 & 1 & 0 \\
\hline
\end{tabular}

\begin{tabular}{|c|c|c|c|c|}
\hline \multirow{2}{*}{$\begin{array}{c}\text { ME } \\
\mathrm{y}\end{array}$} & & WIy1 & WIy2 & WIy3 \\
\hline 1 & & 0 & 0 & 1 \\
0 & & 1 & 0 & 0 \\
0 & & 1 & 0 & 1 \\
1 & & 1 & 0 & 0 \\
0 & & 1 & 0 & 0 \\
1 & & 0 & 0 & 1 \\
\hline & WSy & & & \\
\hline
\end{tabular}

Table 7. Data analysis for $1200 \mathrm{rpm}$ in $\mathrm{z}$ axis

\begin{tabular}{|c|c|c|c|}
\hline $\begin{array}{c}\text { No } \\
\text { re- } \\
\text { sid. }\end{array}$ & $\begin{array}{c}\text { MDz } \\
1\end{array}$ & $\begin{array}{c}\mathrm{MDz} \\
2\end{array}$ & $\begin{array}{c}\mathrm{MDz} \\
3\end{array}$ \\
\hline 1 & 1 & 1 & 0 \\
2 & 1 & 0 & 0 \\
3 & 1 & 0 & 1 \\
4 & 0 & 1 & 1 \\
5 & 1 & 1 & 1 \\
6 & 1 & 1 & 1 \\
\hline
\end{tabular}

\begin{tabular}{|c|c|c|c|c|}
\hline \multicolumn{1}{c|}{$\begin{array}{c}\text { ME } \\
\mathrm{z}\end{array}$} & & WIz1 & WIz2 & WIz3 \\
\hline 1 & & 0 & 0 & 1 \\
0 & & 1 & 0 & 0 \\
0 & & 1 & 0 & 1 \\
1 & & 1 & 0 & 0 \\
1 & & 0 & 0 & 0 \\
1 & & 0 & 0 & 0 \\
\hline & WSz & & & \\
\hline
\end{tabular}

Table 8. Data analysis for $2500 \mathrm{rpm}$ in $\mathrm{x}$ axis

\begin{tabular}{|c|c|c|c|}
\hline $\begin{array}{c}\text { No } \\
\text { re- } \\
\text { sid. }\end{array}$ & $\begin{array}{c}\text { MDx } \\
1\end{array}$ & $\begin{array}{c}\text { MDx } \\
2\end{array}$ & $\begin{array}{c}\text { MDx } \\
3\end{array}$ \\
\hline 1 & 1 & 1 & 0 \\
2 & 1 & 1 & 1 \\
3 & 1 & 1 & 1 \\
4 & 0 & 0 & 1 \\
5 & 1 & 0 & 0 \\
6 & 1 & 1 & 1 \\
\hline
\end{tabular}

\begin{tabular}{|c|c|c|c|c|}
\hline \multicolumn{1}{|c|}{$\begin{array}{c}\text { ME } \\
\mathrm{x}\end{array}$} & WIx1 & WIx2 & WIx3 \\
\hline 0 & & 1 & 1 & 0 \\
1 & & 0 & 0 & 0 \\
1 & & 0 & 0 & 0 \\
1 & & 1 & 1 & 0 \\
0 & & 1 & 0 & 0 \\
1 & & 0 & 0 & 0 \\
\hline & WSx & & & \\
\hline
\end{tabular}

The individual MDn reference data were compared with resides of the tested Men 's signal, obtaining information on existing relations. In the case of compliance (eg MDx1 (1) and MEx (1)) for $1200 \mathrm{rpm}$ (Table 5), the value of WIx1 (1) is 0 . In the case of non-compliance (eg MDx1 (2) and MEx (2)), the value of WIx1 (2) is 1.

By analyzing specific measurement data for the engine, a percentage probability of its state was obtained. Data analysis for identified malfunctions in the form of time gap in fuel injection and air leak in one of engine cylinders is shown in Tables 5-7. Show case data analysis for 1200 rpm, whereas Tables 8-10 show data analysis for $2500 \mathrm{rpm}$.
Identification matrices allow to identify time gap in fuel injection with $100 \%$ certainty (in $\mathrm{x}, \mathrm{y}, \mathrm{z}$ axes) and an air leak within the engine cylinder with $67 \%$ probability (in $x$, $\mathrm{y}, \mathrm{z}$ axes).

\begin{tabular}{|c|c|c|c|c|c|c|c|c|}
\hline $\begin{array}{l}\text { No } \\
\text { re- } \\
\text { sid. }\end{array}$ & $\begin{array}{c}\text { MDy } \\
1\end{array}$ & $\begin{array}{c}\text { MDy } \\
2\end{array}$ & $\begin{array}{c}\text { MDy } \\
3\end{array}$ & $\begin{array}{c}\mathrm{ME} \\
\mathrm{y}\end{array}$ & & WIy1 & WIy2 & $\begin{array}{c}\text { WIy } \\
3\end{array}$ \\
\hline 1 & 1 & 0 & 0 & 0 & & 1 & 0 & 0 \\
\hline 2 & 1 & 1 & 1 & 1 & & 0 & 0 & 0 \\
\hline 3 & 1 & 1 & 1 & 1 & & 0 & 0 & 0 \\
\hline 4 & 0 & 0 & 0 & 0 & & 0 & 0 & 0 \\
\hline 5 & 1 & 1 & 0 & 0 & & 1 & 1 & 0 \\
\hline 6 & 1 & 1 & 1 & 1 & & 0 & 0 & 0 \\
\hline & & & & & $\begin{array}{l}\text { WSy } \\
{[\%]}\end{array}$ & 67 & 83 & 100 \\
\hline
\end{tabular}

Table 10. Data analysis for $2500 \mathrm{rpm}$ in y axis

\begin{tabular}{|c|c|c|c|c|c|c|c|c|}
\hline $\begin{array}{l}\text { No } \\
\text { re- } \\
\text { sid. }\end{array}$ & $\begin{array}{c}\mathrm{MDz} \\
1\end{array}$ & $\begin{array}{c}\mathrm{MDz} \\
2\end{array}$ & $\begin{array}{c}\mathrm{MDz} \\
3\end{array}$ & $\begin{array}{c}\mathrm{ME} \\
\mathrm{z}\end{array}$ & & WIz1 & WIz2 & WIz3 \\
\hline 1 & 1 & 0 & 1 & 1 & & 0 & 1 & 0 \\
\hline 2 & 1 & 1 & 0 & 0 & & 1 & 1 & 0 \\
\hline 3 & 1 & 1 & 1 & 1 & & 0 & 0 & 0 \\
\hline 4 & 0 & 1 & 1 & 1 & & 1 & 0 & 0 \\
\hline 5 & 1 & 1 & 0 & 0 & & 1 & 1 & 0 \\
\hline 6 & 1 & 1 & 1 & 1 & & 0 & 0 & 0 \\
\hline & & & & & $\begin{array}{l}\mathrm{WSz} \\
{[\%]}\end{array}$ & 50 & 50 & 100 \\
\hline
\end{tabular}

As shown by the tests, the master data matrices should be determined for specific engine speed values, which can be seen by comparing the Table $5(1200 \mathrm{rpm})$ and Table 8 (2500 rpm).

\section{Summary and conclusions}

The presented research has shown that it is possible to identify engine malfunctions by analyzing the harmonic components of vehicle chassis vibrations with the use of residuals. Two distinct engine failures were purposefully introduced to an investigated spark-ignition engine mounted in RZR 1000 ATV-time gap in fuel injection and air leak in engine cylinder. Research was conducted for different engine speeds operating in idle conditions.

Differences in spectral lines stemming from engine malfunctions were noted when analyzing relative values of harmonic amplitude components. This allowed the authors to formulate a reasoning matrix for identifying engine failure basing on comparative analysis of harmonic components. In future research, it would seem beneficial to conduct a similar analysis of harmonic components for different engine speeds and to specify a diagnostic criterion.

\section{Nomenclature}

$\mathrm{x}(\mathrm{t})$ time course representing the analyzed input signal

$\tau$ time window position in function of time

F frequency

$\begin{array}{ll}\mathrm{T} & \text { time } \\ \mathrm{f}_{\mathrm{s}} & \text { input signal sampling frequency }\end{array}$ 


\section{Bibliography}

[1] AHMAD, TAGHIZADEH-ALISARAEI, ALIREZA, MAHDAVIAN, Fault detection of injectors in diesel engines using vibration time-frequency analysis, 2019. Applied Acoustics. 2019, 143, 48-58.

[2] ETTEFAGH, M.M., SADEGHI, M.H., PIROUZPANAH, V., ARJMANDI TASH, H. Knock detection in spark ignition engines by vibration analysis of cylinder block: A parametric modeling approach. Mech Syst Signal Process. 2008, 22, 1495-514. DOI: 10.1016/j.ymssp.2007.11.027

[3] ANTONI, J. Cyclostationarity by examples. Mech Syst Signal Process. 2009, 23, 987-1036. DOI: 10.1016/ j.ymssp.2008.10.010

[4] GENG, Z., CHEN, J., HULL, J.B., BARRY HULL, J. Analysis of engine vibration and design of an applicable diagnosing approach. Int J Mech Sci. 2003, 45, 1391-1410. DOI: 10.1016/j.ijmecsci.2003.09.012

Jarosław Mamala, DSc., DEng. - Faculty of Mechanical Engineering, Opole University of Technology.

e-mail: j.mamala@po.opole.pl

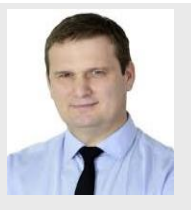

Krzysztof Prażnowski, DEng. - Faculty of Mechanical Engineering, Opole University of Technology. e-mail:k.praznowski@po.opole.pl
[5] KORBICZ, J., KOŚCIELNY, J., KOWALCZUK, Z., CHOLEWA, W. Diagnostyka procesów. Modele, metody sztucznej inteligencji, zastosowania. WNT. Warszawa 2002.

[6] CEMPEL, C. Drgania mechaniczne - wprowadzenie. Wydawnictwo Politechniki Poznańskiej. Poznań 1984.

[7] PRAŻNOWSKI, K., MAMALA, J. Problems in assessing pneumatic wheel unbalance of a passenger car determined with test road in normal conditions. SAE Technical Paper. 2017.

[8] PRAŻNOWSKI, K., MAMALA, J. Classification of the road surface condition on the basis of vibrations of the sprung mass in a passenger car. IOP Conference Series: Materials Science and Engineering, Zakopane 2016.

[9] BROL, S., MAMALA, J. Application of spectral and wavelet analysis in power train system diagnostic. SAE Technical Paper. 2010.

[10] WAJAND, J.A., WAJAND, J.T. Tłokowe silniki spalinowe średnio i szybkoobrotowe. WNT. Warszawa 2000.

Mariusz Graba, DEng. - Faculty of Mechanical Engineering, Opole University of Technology.

e-mail:m.graba@po.opole.pl
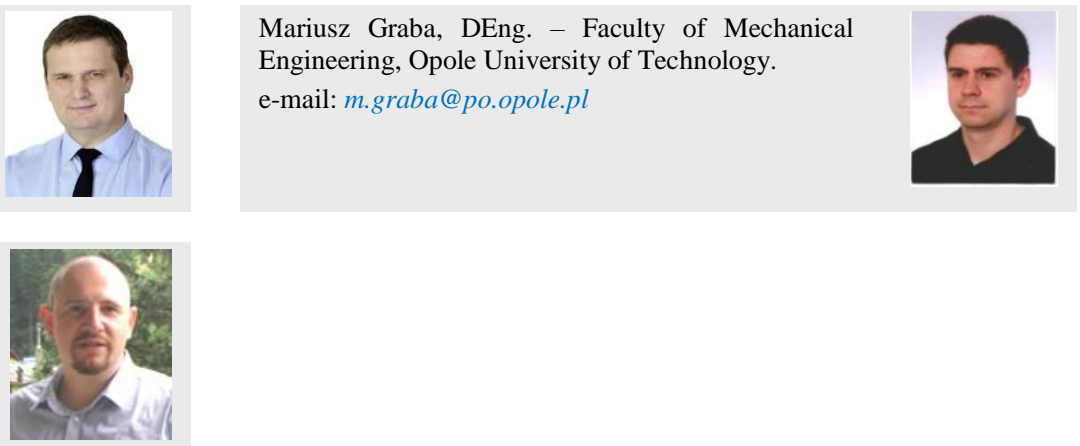